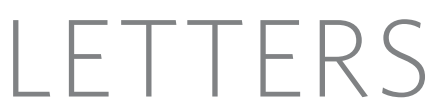

\title{
Damage to the prefrontal cortex increases utilitarian moral judgements
}

\author{
Michael Koenigs ${ }^{1} \dagger^{\star}$, Liane Young ${ }^{2 \star}$, Ralph Adolphs ${ }^{1,3}$, Daniel Tranel ${ }^{1}$, Fiery Cushman $^{2}$, Marc Hauser $^{2}$ \\ \& Antonio Damasio ${ }^{1,4}$
}

The psychological and neurobiological processes underlying moral judgement have been the focus of many recent empirical studies ${ }^{1-11}$. Of central interest is whether emotions play a causal role in moral judgement, and, in parallel, how emotion-related areas of the brain contribute to moral judgement. Here we show that six patients with focal bilateral damage to the ventromedial prefrontal cortex (VMPC), a brain region necessary for the normal generation of emotions and, in particular, social emotions ${ }^{12-14}$, produce an abnormally 'utilitarian' pattern of judgements on moral dilemmas that pit compelling considerations of aggregate welfare against highly emotionally aversive behaviours (for example, having to sacrifice one person's life to save a number of other lives $)^{7,8}$. In contrast, the VMPC patients' judgements were normal in other classes of moral dilemmas. These findings indicate that, for a selective set of moral dilemmas, the VMPC is critical for normal judgements of right and wrong. The findings support a necessary role for emotion in the generation of those judgements.

The basis of our moral judgements has been a long-standing focus of philosophical inquiry and, more recently, active empirical investigation. In a departure from traditional rationalist approaches to moral cognition that emphasize the role of conscious reasoning from explicit principles ${ }^{15}$, modern accounts have proposed that emotional processes, conscious or unconscious, may also play an important role ${ }^{16,17}$. Emotion-based accounts draw support from multiple lines of empirical work: studies of clinical populations reveal an association between impaired emotional processing and disturbances in moral behaviour ${ }^{1-4}$; neuroimaging studies consistently show that tasks involving moral judgement activate brain areas known to process emotions $^{5-9}$; and behavioural studies demonstrate that manipulation of affective state can alter moral judgements ${ }^{10,11}$. However, neuroimaging studies do not settle whether putatively 'emotional' activations are a cause or consequence of moral judgement; behavioural studies in healthy individuals do not address the neural basis of moral judgement; and no clinical studies have specifically examined the moral judgements (as opposed to moral reasoning or moral behaviour) of patients with focal brain lesions. In brief, none of the existing studies establishes that brain areas integral to emotional processes are necessary for the generation of normal moral judgements. As a result, there remains a critical gap in the evidence relating moral judgement, emotion and the brain.

Investigating moral judgements in individuals with focal damage to the ventromedial prefrontal cortex (VMPC) provides a key test. The VMPC projects to basal forebrain and brainstem regions that execute bodily components of emotional responses ${ }^{18}$, and neurons within the VMPC encode the emotional value of sensory stimuli ${ }^{19}$.
Patients with VMPC lesions exhibit generally diminished emotional responsivity and markedly reduced social emotions (for example, compassion, shame and guilt) that are closely associated with moral values $^{1,2,12-14,16}$, and also exhibit poorly regulated anger and frustration tolerance in certain circumstances ${ }^{20,21}$. Despite these patent defects both in emotional response and emotion regulation, the capacities for general intelligence, logical reasoning, and declarative knowledge of social and moral norms are preserved ${ }^{20-23}$. We selected a sample of six patients with adult-onset, focal bilateral VMPC lesions (Fig. 1) as well as both neurologically normal (NC) and brain-damaged comparison (BDC) subjects. Importantly, each of the VMPC patients had striking defects in social emotion but generally intact intellect and normal baseline mood (Tables 1 and 2, see also Supplementary Table 1). In particular, all six VMPC patients had impaired autonomic activity in response to emotionally charged pictures (Table 2), as well as severely diminished empathy, embarrassment and guilt (Table 2). All comparison subjects (NC and BDC) had intact emotional processing.

Subjects evaluated moral dilemmas designed to pit two competing considerations against one another. A paradigmatic dilemma of this type presents subjects with the choice of whether or not to sacrifice one person's life to save the lives of others. One consideration is a utilitarian calculation of how to maximize aggregate welfare, whereas the other is a strong emotional aversion to the proposed action. One model holds that endorsement of the proposed action (the utilitarian response) requires the subject to overcome an emotional response against inflicting direct harm to another person (a 'personal' harm $^{7,8}$ ). If emotional responses mediated by VMPC are indeed a critical influence on moral judgement, individuals with VMPC lesions should exhibit an abnormally high rate of utilitarian judgements on the emotionally salient, or 'personal', moral scenarios (for example, pushing one person off a bridge to stop a runaway boxcar from hitting five people), but a normal pattern of judgements on the less emotional, or 'impersonal', moral scenarios (for example, turning a runaway boxcar away from five people but towards one person). If, alternatively, emotion does not play a causal role in the generation of moral judgements but instead follows from the judgements ${ }^{24,25}$, then individuals with emotion defects due to VMPC lesions should show a normal pattern of judgements on all scenarios.

To test for between-group differences in the probability of utilitarian responses given for each scenario type (non-moral, impersonal moral, personal moral), we used a logistic regression fitted with the generalized estimating equations method (Fig. 2). There were no significant differences between groups on the non-moral or impersonal moral scenarios (all $P$ values $>0.29$, corrected for multiple

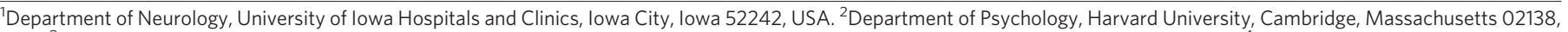

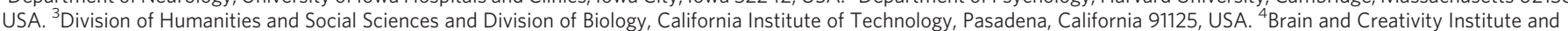

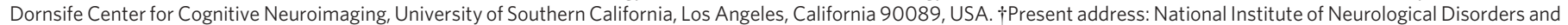
Stroke, National Institutes of Health, Bethesda, Maryland 20892-1440, USA.

*These authors contributed equally to this work.
} 

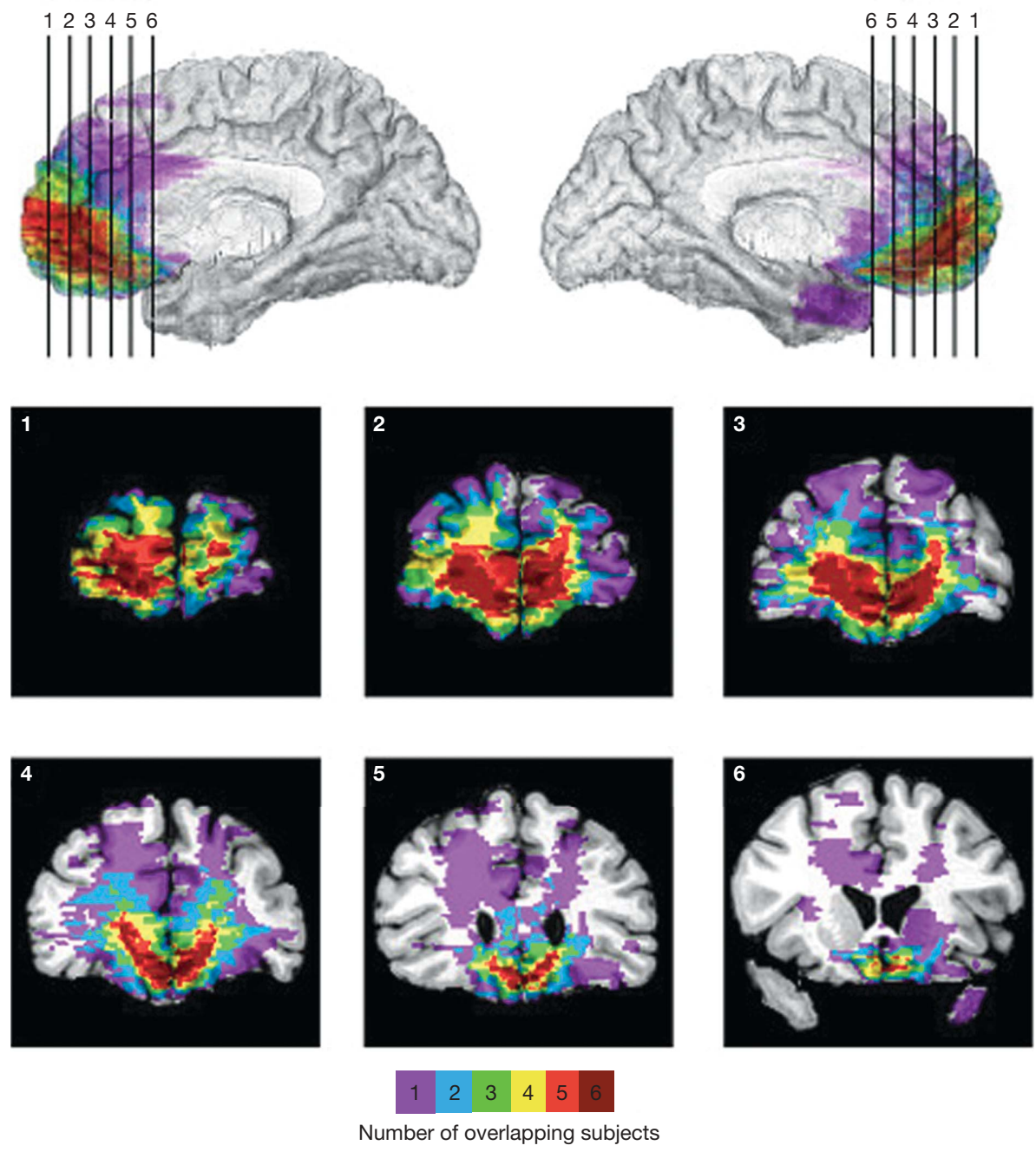

Figure 1 | Lesion overlap of VMPC patients. Lesions of the six VMPC patients displayed in mesial views and coronal slices. The colour bar

comparisons). In contrast, for personal moral scenarios, the VMPC group was more likely to endorse the proposed action than either the NC group (odds ratio $=2.81 ; P=0.04$, corrected) or BDC group (odds ratio $=3.30 ; P=0.006$, corrected). There was no difference between the NC and $\mathrm{BDC}$ groups (odds ratio $=0.85 ; P=0.68$, uncorrected). These data indicate that the VMPC group's responses differed only for personal moral scenarios, suggesting that VMPCmediated processes affect only those moral judgements involving emotionally salient actions.

In a more fine-grained analysis, we examined response patterns within the personal moral scenarios. For seven out of the 21 personal

Table $1 \mid$ VMPC patient neuropsychological data

\begin{tabular}{lrrrrrrrrc}
\hline Subject & \multicolumn{3}{c}{ WAIS-III } & \multicolumn{2}{c}{ WMS-III } & TT & WCST & Stroop & BDI \\
& VIQ & PIQ & FSIQ & GMI & WMI & & & & \\
\hline 1 & 142 & 134 & 143 & 109 & 124 & 44 & 6 & 70 & 0 \\
2 & 89 & 97 & 91 & 59 & 102 & 44 & 6 & 49 & 3 \\
3 & 111 & 96 & 104 & 74 & 105 & 44 & 6 & 67 & 10 \\
4 & 108 & 102 & 106 & 109 & 124 & 44 & 6 & 57 & 1 \\
5 & 110 & 107 & 109 & 105 & 102 & 44 & 6 & 54 & 8 \\
6 & 89 & 80 & 84 & 96 & 88 & 44 & 0 & 77 & 7 \\
\hline
\end{tabular}

WAIS-III, Wechsler Adult Intelligence Scale-III scores (VIQ, verbal IQ; PIQ, performance IQ; FSIQ, full-scale IQ). WMS-III, Wechsler Memory Scale-III scores (GMI, general memory index WMI, working memory index). TT, Token Test (from the Multilingual Aphasia Examination), a measure of basic verbal comprehension. WCST, Wisconsin Card Sort Test categories, a measure of executive function. Stroop, T-score on the Interference trial of the Stroop ColourWord Test, a measure of response inhibition. BDI, Beck Depression Inventory, a measure of baseline mood. All patients were within normal ranges except for subjects 2 and 3 on GMI and subject 6 on WCST and Stroop. indicates the number of overlapping lesions at each voxel.

moral scenarios, both comparison groups were at 100\% agreement in their judgements. An additional eighth scenario elicited 100\% agreement from the BDC group, and near-perfect agreement from the NC group (with only one participant deviating from the shared response). These eight scenarios were therefore classified as 'lowconflict' (for example, abandoning one's baby to avoid the burden of caring for it). The remaining 13 scenarios (none of which elicited $100 \%$ agreement from either comparison group) were classified as 'high-conflict' (for example, smothering one's baby to save a number

Table 2 | VMPC patient social emotion data

\begin{tabular}{lcccc}
\hline Subject & SCRs & Empathy & Embarrassment & Guilt \\
\hline 1 & Impaired & 3 & 3 & 3 \\
2 & Impaired & 3 & 3 & 3 \\
3 & Impaired & 3 & 3 & 3 \\
4 & Impaired & 2 & 2 & 1 \\
5 & Impaired & 3 & 3 & 3 \\
6 & Impaired & 3 & 3 & 3 \\
\hline
\end{tabular}

SCRs, skin conductance responses to emotionally charged socially significant stimuli (for example, pictures of social disasters, mutilations, nudes), using methods previously described ${ }^{12}$. The same SCR experiment was performed in ten of twelve BDC patients, and all ten demonstrated normal SCRs to emotionally charged pictures. A clinical neuropsychologist blind to the hypotheses of the current study rated each VMPC patient's demonstrated capacity for empathy, embarrassment and guilt in his or her personal life. The rating used a four-point scale denoting severity of impairment, where $0=$ normal, $1=$ mild, $2=$ moderate and $3=$ severe. Ratings were based on data derived from spouse or family member reports in the lowa Rating Scales of Personality Change ${ }^{29}$ and from data from clinical interviews. Both of these sources provide direct observations about the patient's basic and social emotions, and include questions about whether the patient experiences and manifests emotions such as sadness, anxiety, empathy, embarrassment and guilt. 


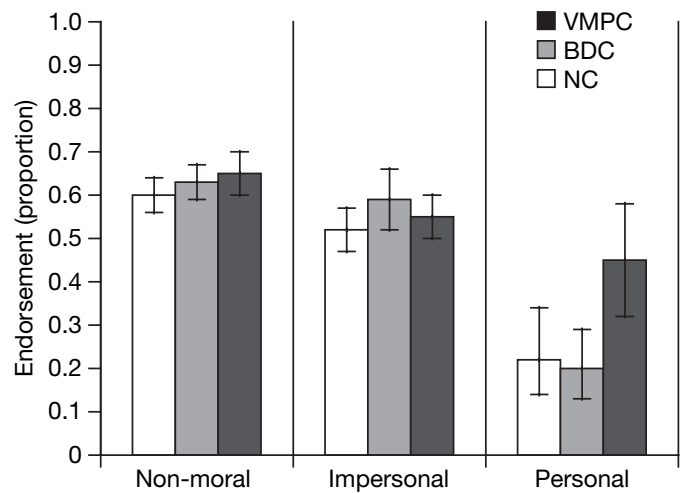

Figure 2 | Moral judgements for each scenario type. Proportions of 'yes' judgements are shown for each subject group. Error bars indicate $95 \%$ confidence intervals. We used three classes of stimuli: non-moral scenarios $(n=18)$, impersonal moral scenarios $(n=11)$, and personal moral scenarios $(n=21)$. On personal moral scenarios, the frequency of endorsing 'yes' responses was significantly greater in the VMPC group than in either comparison group ( $P$ values $<0.05$, corrected $)$.

of people). Reaction-time data support this distinction: response latencies in the NC group on high-conflict scenarios were significantly longer than on low-conflict scenarios ( $t$-test with 19 degrees of freedom, $t(19)=-3.63 ; P=0.002)$.

Like the patients in the comparison groups, the VMPC patients uniformly rejected the proposed action in every one of the lowconflict scenarios (Fig. 3). In contrast, significant differences emerged for the high-conflict scenarios: the VMPC group was more likely to endorse the proposed action than either the NC (odds ratio $=4.70 ; P=0.05$, corrected) or $\mathrm{BDC}$ group (odds ratio $=5.38$; $P=0.02$, corrected), with no difference between the NC and BDC participants (odds ratio $=0.87 ; P=0.77$, uncorrected). Every highconflict personal scenario elicited the same pattern: a greater proportion of the VMPC group endorsed the action than either comparison group.

To recapitulate, VMPC patients' judgements differed from comparison subjects' only for the high-conflict personal moral dilemmas, all of which featured competing considerations of aggregate welfare on the one hand, and, on the other hand, harm to others that would normally evoke a strong social emotion. Low-conflict personal moral scenarios lacked this degree of competition. This difference probably

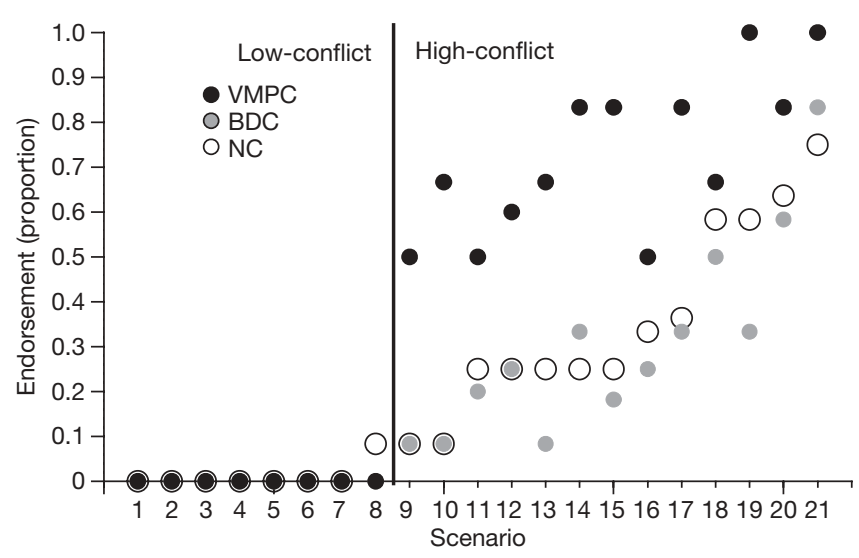

Figure 3 | Moral judgements on individual personal moral scenarios.

Proportions of 'yes' judgements given by each subject group for each of the 21 personal moral scenarios. Individual scenarios (numbered 1-21 on the $x$ axis) are ordered by increasing proportion of 'yes' responses given by the normal comparison group. Responses did not differ between subject groups for the low-conflict scenarios (left of the vertical line). The VMPC group made a greater proportion of 'yes' judgements than either comparison group for every one of the high-conflict scenarios (right of the vertical line). accounts for the greater consensus and faster reaction times on lowconflict personal dilemmas in the comparison groups, and it can also account for the VMPC patients' pattern of judgements. Evidence suggests that knowledge of explicit social and moral norms is intact in individuals with VMPC damage $e^{21,22}$. In the absence of an emotional reaction to harm of others in personal moral dilemmas, VMPC patients may rely on explicit norms endorsing the maximization of aggregate welfare and prohibiting the harming of others. This strategy would lead VMPC patients to a normal pattern of judgements on low-conflict personal dilemmas but an abnormal pattern of judgements on high-conflict personal dilemmas, precisely as was observed. The specificity of this result argues against a general deficit in the capacity for moral judgement following VMPC damage. Rather, VMPC seems to be critical only for moral dilemmas in which social emotions play a pivotal role in resolving moral conflict ${ }^{4,8,16,17}$.

It is important to note that the effects of VMPC damage on emotion processing depend on context. In this study, the VMPC patients' abnormally high rate of utilitarian judgements is attributed to diminished social emotion, whereas in a recent study of the Ultimatum Game, theVMPC patients' abnormally high rate of rejection of unfair monetary offers was attributed to poorly controlled frustration, manifested as exaggerated anger ${ }^{20}$. These seemingly contradictory findings highlight two distinct aspects of emotion impairment that are due to VMPC damage. In most circumstances, VMPC patients exhibit generally blunted affect and a specific defect of social emotions, but in response to direct personal frustration or provocation, VMPC patients may exhibit short-temper, irritability, and anger. In the moral judgement task we report here, participants respond to hypothetical actions and outcomes that elicit social emotions related to concern for others. In the Ultimatum Game, in contrast, participants respond to unfair take-it-or-leave-it offers that trigger frustration. In brief, the tasks in the two studies are different in that the Ultimatum Game involves self-interest in a real behavioural setting, whereas the task in the present study focuses on the interest of others described in a hypothetical scenario.

To conclude, the present findings are consistent with a model in which a combination of intuitive/affective and conscious/rational

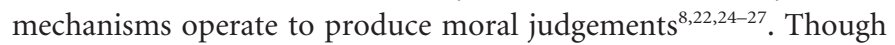
the precise characterization of these potential systems awaits further work, the current results suggest that the VMPC is a critical neural substrate for the intuitive/affective but not for the conscious/rational system.

\section{METHODS}

Subjects. Six patients with bilateral, adult-onset damage to the VMPC and twelve brain-damaged comparison patients who had lesions that excluded structures thought to be important for emotions (VMPC, amygdala, insula, right somatosensory cortices) were recruited from the Patient Registry of the Division of Cognitive Neuroscience at the University of Iowa. Twelve healthy comparison subjects with no brain damage were recruited from the Iowa community. Groups were age-, gender- and ethnicity-matched. All participants gave written informed consent.

Neuroanatomical analysis. The neuroanatomical analysis of VMPC patients (Fig. 1) was based on magnetic resonance data for two subjects (those with lesions due to the surgical resection of orbital meningiomas) and on computerized tomography data for the other four subjects (with lesions due to rupture of an anterior communicating artery aneurysm). All neuroimaging data were obtained in the chronic epoch. Each patient's lesion was reconstructed in three dimensions using Brainvox ${ }^{28}$. Using the MAP-3 technique, the lesion contour for each patient was manually warped into a normal template brain. The overlap of lesions in this volume, calculated by the sum of $n$ lesions overlapping on any single voxel, is colour-coded in Fig. 1.

Stimuli and task. Participants made judgements on a series of 50 hypothetical scenarios, which were adapted from a previously published set $^{8}$. See the Supplementary Information for the full text of the actual scenarios used. Each scenario was presented as text through a series of three screens. The first two described the scenario and the third posed a question about a hypothetical action related to the scenario ("Would you ... in order to ...?"). Participants read and responded at their own pace, pressing an 'up' arrow key to advance from one 
screen to the next, and a 'yes' or 'no' button to indicate an answer to the question. 'Yes' responses always indicated commission of the proposed action. There was no time limit for reading the scenario description (screens 1 and 2). Participants had a maximum of $25 \mathrm{~s}$ to read the final question screen and respond.

We used three classes of stimuli: non-moral scenarios $(n=18)$, and two classes of moral scenarios subdivided according to the emotional reaction elicited by the proposed action: 'personal' $(n=21)$ or 'impersonal' $(n=11)$, as described previously $y^{7,8}$. To validate this subdivision, an independent group of ten neurologically normal subjects rated the emotional salience of the actions proposed in the moral scenarios. The actions described in personal scenarios were rated as significantly more emotionally salient than the actions described in impersonal scenarios (means were 5.9 and 3.0 on a scale from 1 to 7 , respectively; $t(31)=-8.90, P<0.0001$ ). Within either class of moral scenarios (personal or impersonal), it was not valid to separately analyse judgements based on the emotional salience of the proposed action (that is 'high-emotion' versus 'lowemotion' scenarios) because emotionality ratings were remarkably similar for scenarios within each class: 9 of the 11 impersonal scenarios received a mean emotion rating between 1.1 and 3.0, while 20 of the 21 personal scenarios received a mean emotion rating between 5.3 and 6.7.

We further subdivided the personal moral scenarios into 'low-conflict' and 'high-conflict' on the basis of the reaction times and consensus produced on them by normal subjects. Reaction times on high-conflict scenarios were significantly longer than on low-conflict scenarios $(t(19)=-3.63, P=0.002)$. Importantly, low-conflict and high-conflict scenarios did not differ in their rated emotional salience $(t(19)=-0.85, P=0.41)$.

\section{Received 3 November 2006; accepted 17 February 2007.}

\section{Published online 21 March 2007.}

1. Eslinger, P. J., Grattan, L. M. \& Damasio, A. R. Developmental consequences of childhood frontal lobe damage. Arch. Neurol. 49, 764-769 (1992).

2. Anderson, S. W., Bechara, A., Damasio, H., Tranel, D. \& Damasio, A. R. Impairment of social and moral behavior related to early damage in human prefrontal cortex. Nature Neurosci. 2, 1032-1037 (1999).

3. Blair, R. J. R. A cognitive developmental approach to morality: investigating the psychopath. Cognition 57, 1-29 (1995).

4. Mendez, M. F., Anderson, E. \& Shapira, J. S. An investigation of moral judgment in frontotemporal dementia. Cogn. Behav. Neurol. 18, 193-197 (2005).

5. Moll, J., de Oliveira-Souza, R., Bramati, I. E. \& Grafman, J. Functional networks in emotional moral and nonmoral social judgments. Neuroimage 16, 696-703 (2002).

6. Heekeren, H. R., Wartenburger, I., Schmidt, H., Schwintowski, H. P. \& Villringer, A. An fMRI study of simple ethical decision-making. Neuroreport 14, 1215-1219 (2003).

7. Greene, J. D., Sommerville, R. B., Nystrom, L. E., Darley, J. M. \& Cohen, J. D. An fMRI investigation of emotional engagement in moral judgment. Science 293, 2105-2108 (2001).

8. Greene, J. D., Nystrom, L. E., Engell, A. D., Darley, J. M. \& Cohen, J. D. The neural bases of cognitive conflict and control in moral judgment. Neuron 44, 389-400 (2004).

9. Luo, Q. et al. The neural basis of implicit moral attitude-An IAT study using eventrelated fMRI. Neuroimage 30, 1449-1457 (2006).

10. Wheatley, T. \& Haidt, J. Hypnotic disgust makes moral judgments more severe. Psychol. Sci. 16, 780-784 (2005).

11. Valdesolo, P. \& DeSteno, D. Manipulations of emotional context shape moral judgment. Psychol. Sci. 17, 476-477 (2006).
12. Damasio, A. R., Tranel, D. \& Damasio, H. Individuals with sociopathic behavior caused by frontal damage fail to respond autonomically to social stimuli. Behav. Brain Res. 41, 81-94 (1990).

13. Damasio, A. R. Looking for Spinoza: Joy, Sorrow, and the Feeling Brain (Harcourt, New York, 2003).

14. Beer, J. S., Heerey, E. H., Keltner, D., Scabini, D. \& Knight, R. T. The regulatory function of self-conscious emotion: Insights from patients with orbitofrontal damage. J. Pers. Soc. Psychol. 85, 594-604 (2003).

15. Kohlberg, L. Essays on Moral Development Vol. 1 The Philosophy of Moral Development (Harper Row, New York, 1981).

16. Damasio, A. R. Descartes' Error: Emotion, Reason, and the Human Brain (Penguin, New York, 1994).

17. Haidt, J. The emotional dog and its rational tail: A social intuitionist approach to moral judgment. Psychol. Rev. 108, 814-834 (2001).

18. Ongur, D. \& Price, J. L. The organization of networks within the orbital and medial prefrontal cortex of rats, monkeys and humans. Cereb. Cortex 10, 206-219 (2000).

19. Rolls, E. The orbitofrontal cortex and reward. Cereb. Cortex 3, 284-294 (2000).

20. Koenigs, M. \& Tranel, D. Irrational economic decision-making after ventromedial prefrontal damage: evidence from the ultimatum game. J. Neurosci. 27, 951-956 (2007).

21. Anderson, S. W., Barrash, J., Bechara, A. \& Tranel, D. Impairments of emotion and real-world complex behavior following childhood- or adult-onset damage to ventromedial prefrontal cortex. J. Int. Neuropsychol. Soc. 12, 224-235 (2006).

22. Saver, J. L. \& Damasio, A. R. Preserved access and processing of social knowledge in a patient with acquired sociopathy due to ventromedial frontal damage. Neuropsychologia 29, 1241-1249 (1991).

23. Burgess, P. W. et al. The case for the development and use of "ecologically valid" measures of executive functions in experimental and clinical neuropsychology. J. Int. Neuropsychol. Soc. 12, 194-209 (2006).

24. Hauser, M. D. Moral Minds: How Nature Designed our Universal Sense of Right and Wrong (Ecco/Harper Collins, New York, 2006).

25. Mikhail, J. Rawls' Linguistic Analogy. PhD thesis, Cornell Univ. (2000).

26. Cushman, F. A., Young, L. L. \& Hauser, M. D. The role of conscious reasoning and intuition in moral judgments: Testing three principles of permissible harm. Psychol. Sci. 17, 1082-1089 (2006).

27. Hauser, M. D., Cushman, F. A., Young, L. L., Jin, K-X. \& Mikhail, J. A dissociation between moral judgments and justifications. Mind Language 22, 1-21 (2006).

28. Frank, R. J., Damasio, H. \& Grabowski, T. J. Brainvox: an interactive, multimodal visualization and analysis system for neuroanatomical imaging. Neuroimage 5 , 13-30 (1997).

29. Barrash, J. \& Anderson, S. W. The lowa Rating Scales of Personality Change (Department of Neurology, Univ. lowa, lowa, 1993).

Supplementary Information is linked to the online version of the paper at www.nature.com/nature.

Acknowledgements We thank $H$. Damasio for making available neuroanatomical analyses of lesion patients and for preparing Fig. 1. We thank all participants for their participation in the experiments and R. Saxe for comments on the manuscript. This work was supported by grants from the National Institutes of Health, the National Science Foundation, the Gordon and Betty Moore Foundation, and the Guggenheim Foundation.

Author Information Reprints and permissions information is available at www.nature.com/reprints. The authors declare no competing financial interests. Correspondence and requests for materials should be addressed to R.A. (radolphs@hss.caltech.edu). 


\section{Supplementary Table 1. Demographic and clinical data for each VMPC patient and summary data for each group (VMPC, BDC, NC)}

\begin{tabular}{|c|c|c|c|c|c|c|}
\hline PATIENT & AGE & $\begin{array}{c}\text { EDUCATION } \\
\text { (years) }\end{array}$ & SEX & HANDED & $\begin{array}{c}\text { CHRONICITY } \\
\text { (years) }\end{array}$ & ETIOLOGY \\
\hline 1 & 66 & 14 & $M$ & +100 & 30 & $\begin{array}{c}\text { Meningioma } \\
\text { resection }\end{array}$ \\
\hline 2 & 63 & 9 & $M$ & +100 & 15 & $\begin{array}{c}\text { SAH; ACoA } \\
\text { aneurysm }\end{array}$ \\
\hline 3 & 43 & 13 & $\mathrm{~F}$ & +100 & 10 & $\begin{array}{c}\mathrm{SAH} ; \mathrm{ACoA} \\
\text { aneurysm }\end{array}$ \\
\hline 4 & 57 & 14 & $\mathrm{~F}$ & +100 & 7 & $\begin{array}{c}\text { SAH; ACoA } \\
\text { aneurysm }\end{array}$ \\
\hline 5 & 60 & 13 & $\mathrm{~F}$ & +100 & 7 & $\begin{array}{l}\text { Meningioma } \\
\text { resection }\end{array}$ \\
\hline 6 & 66 & 12 & M & +100 & 7 & $\begin{array}{c}\text { SAH; ACoA } \\
\text { aneurysm }\end{array}$ \\
\hline $\begin{array}{c}\text { VMPC mean } \\
\text { (s.d) }\end{array}$ & $\begin{array}{l}59.2 \\
(8.7)\end{array}$ & $\begin{array}{l}12.5 \\
(1.9)\end{array}$ & $3 \mathrm{M} / 3 \mathrm{~F}$ & $6 \mathrm{R} / 0 \mathrm{~L}$ & $\begin{array}{l}12.7 \\
(9.0)\end{array}$ & \\
\hline $\begin{array}{l}\text { BDC mean } \\
\text { (s.d) }\end{array}$ & $\begin{array}{c}59.4 \\
(13.7)\end{array}$ & $\begin{array}{l}15.9 \\
(2.2)\end{array}$ & $6 \mathrm{M} / 6 \mathrm{~F}$ & $10 \mathrm{R} / 2 \mathrm{~L}$ & $\begin{array}{c}6.6 \\
(9.2)\end{array}$ & See legend \\
\hline $\begin{array}{l}\text { NC mean } \\
\text { (s.d) }\end{array}$ & $\begin{array}{l}58.4 \\
(9.0)\end{array}$ & $\mathrm{n} / \mathrm{a}$ & $6 \mathrm{M} / 6 \mathrm{~F}$ & $\mathrm{n} / \mathrm{a}$ & $\mathrm{n} / \mathrm{a}$ & $\mathrm{n} / \mathrm{a}$ \\
\hline
\end{tabular}

Handed refers to handedness as measured with the modified Oldfield-Geschwind questionnaire, which provides an index ranging from full right-handedness $(+100)$ to full left-handedness $(-100)$. Chronicity refers to the length of time between lesion onset and execution of the current experiment. Etiology refers to the cause of brain lesion. SAH, subarachnoid hemorrhage; ACoA, anterior communicating artery. $\mathrm{n} / \mathrm{a}$, data not available or not applicable. Etiology in the BDC group: cerebrovascular accident $(n=7)$; benign tumor resection $(n=3)$; surgical resection for epilepsy treatment $(n=1)$; surgical resection of subdural hematoma $(n=1)$. Lesion location in the BDC group: occipital $(n=4)$; temporoparietal $(n=3)$; lateral frontal $(n=3)$; anterolateral temporal $(n=1)$; dorsomedial frontal $(n=1)$.

\section{Stimuli}

Stimuli are divided into three groups: non-moral, impersonal moral, and personal moral. All moral scenarios include mean ratings of emotional aversion to the proposed action (see Methods). Personal moral scenarios are also labeled as either low-conflict or highconflict based on comparison group response data. Personal moral scenario numbers correspond to Figure 3.

\section{Non-Moral Scenarios:}

\section{Standard Turnips}

You are a farm worker driving a turnip-harvesting machine. You are approaching two diverging paths. 
By choosing the path on the left you will harvest ten bushels of turnips. By choosing the path on the right you will harvest twenty bushels of turnips. If you do nothing your turnip-harvesting machine will turn to the left

Would you turn your turnip-picking machine to the right in order to harvest twenty bushels of turnips instead of ten?

\section{Plant Transport}

You are bringing home a number of plants from a store that is about two miles from your home. The trunk of your car, which you've lined with plastic to catch the mud from the plants, will hold most of the plants you've purchased.

You could bring all the plants home in one trip, but this would require putting some of the plants in the back seat as well as in the trunk. By putting some of the plants in the back seat you will ruin your fine leather upholstery which would cost thousands of dollars to replace.

Would you make two trips home in order to avoid ruining the upholstery of your car?

\section{Scheduling}

You are in charge of scheduling appointments in a dentist's office. Two people, Mr. Morris and Mrs. Santiago have called to make appointments for next Monday. The only available times for next Monday are at 10:00 AM and at 3:00 PM.

Mr. Morris's schedule is rather flexible. He can have his appointment either at 10:00 AM or at 3:00 PM. Mrs. Santiago's schedule is less flexible. She can only have her appointment at 10:00 AM.

Would you schedule Mr. Morris for 3:00 PM so that both he and Mrs. Santiago can have their appointments next Monday?

\section{Generic Brand}

You have a headache. You go to the pharmacy with the intention of buying a particular name-brand headache medicine. When you get there you discover that the pharmacy is out of the brand you were looking for.

The pharmacist, whom you've known for a long time and in whom you have a great deal of trust, tells you that he has in stock a generic product which is, in his words, "exactly the same" as the product you had originally intended to buy. 
Would you purchase the generic brand instead of searching further for the name-brand product you were looking for?

\section{Brownies}

You have decided to make a batch of brownies for yourself. You open your recipe book and find a recipe for brownies.

The recipe calls for a cup of chopped walnuts. You don't like walnuts, but you do like macadamia nuts. As it happens, you have both kinds of nuts available to you.

Would you substitute macadamia nuts for walnuts in order to avoid eating walnuts?

\section{Train or Bus}

You need to travel from New York to Boston in order to attend a meeting that starts at 2:00 PM. You can take either the train or the bus.

The train will get you there just in time for your meeting no matter what. The bus is scheduled to arrive an hour before your meeting, but the bus is occasionally several hours late because of traffic. It would be nice to have an extra hour before the meeting, but you cannot afford to be late.

Would you take the train instead of the bus in order to ensure your not being late for your meeting?

\section{Computer}

You are looking to buy a new computer. At the moment the computer that you want costs $\$ 1000$. A friend who knows the computer industry has told you that this computer's price will drop to $\$ 500$ next month.

If you wait until next month to buy your new computer you will have to use your old computer for a few weeks longer than you would like to. Nevertheless you will be able to do everything you need to do using your old computer during that time.

Would you use your old computer for a few more weeks in order to save $\$ 500$ on the purchase of a new computer?

\section{Survey}


A representative of a reputable, national survey organization calls you at your home while you are having a quiet dinner by yourself.

The representative explains that if you are willing to spend a half an hour answering questions about a variety of topics her organization will send you a check for $\$ 200$.

Would you interrupt your dinner in order to earn $\$ 200$ ?

\section{Coupons}

You have gone to a bookstore to buy $\$ 50$ worth of books. You have with you two coupons.

One of these coupons gives you $30 \%$ off of your purchase price. This coupon expires tomorrow. The other coupon gives you $25 \%$ off your purchase price, and this coupon does not expire for another year.

Would you use the $30 \%$-off coupon for your present purchase so that you will have another coupon to use during the coming year?

\section{Scenic Route}

An old friend has invited you to spend the weekend with him at his summer home some ways up the coast from where you are. You intend to travel there by car, and there are two routes that you can take: the highway and the coastal road.

The highway will get you to your friend's house in about three hours, but the scenery along the highway is very boring. The coastal route will get you to your friend's house in about three hours and fifteen minutes, and the scenery along the coastal road is breathtakingly beautiful.

Would you take the coastal route in order to observe the beautiful scenery as you drive?

\section{Reversed Turnips}

You are a farm worker driving a turnip-harvesting machine. You are approaching two diverging paths.

By choosing the path on the left you will harvest thirty bushels of turnips. By choosing the path on the right you will harvest fifteen bushels of turnips. If you do nothing your turnip-picking machine will turn to the left. 
Would you turn your turnip-harvesting machine to the right in order to harvest fifteen bushels of turnips instead of thirty?

\section{Investment Offer}

You are at home one day when the mail arrives. You receive a letter from a reputable corporation that provides financial services. They have invited you to invest in a mutual fund, beginning with an initial investment of one thousand dollars.

As it happens, you are familiar with this particular mutual fund. It has not performed very well over the past few years, and, based on what you know, there is no reason to think that it will perform any better in the future.

Would you invest a thousand dollars in this mutual fund in order to make money?

\section{Broken VCR}

You have brought your broken VCR to the local repair shop. The woman working at the shop tells you that it will cost you about $\$ 100$ to have it fixed.

You noticed in the paper that morning that the electronics shop next door is having a sale on VCR's and that a certain new VCR which is slightly better than your old one is on sale for $\$ 100$.

Would you have your old VCR fixed in order to avoid spending money on a new one?

\section{Choosing Classes}

You are beginning your senior year of college. In order to fulfill your graduation requirements you need to take a history class and a science class by the end of the year.

During the fall term, the history class you want to take is scheduled at the same time as the science class you want to take. During the spring term the same history class is offered, but the science class is not.

Would you take the history class during the fall term in order to help you fulfill your graduation requirements?

\section{Raffle}

You've decided to buy a raffle ticket to support a local charity. They are separately raffling off two different cars: Car A and Car B. You have decided to buy one raffle 
ticket. You are a serious and knowledgeable car enthusiast, and you think that these two cars are equally good.

Because there have been a lot of adds for Car B on TV recently, many more people have chosen to buy tickets for the Car B raffle. Since more people have bought tickets for the Car B raffle, your chances of winning are better in the Car A raffle than in the Car B raffle.

Would you buy a ticket for the Car B raffle in order to win a car?

\section{Jogging}

You intend to accomplish two things this afternoon: going for a jog and doing some paperwork. In general you prefer to get your work done before you exercise.

The weather is nice at the moment, but the weather forecast says that in a couple of hours it will start to rain. You very much dislike jogging in the rain, but you don't care what the weather is like while you do paperwork.

Would you do your paperwork now with the intention of jogging in a couple of hours in order to get your work done before you exercise?

\section{Food Prep}

You are preparing pasta with fresh vegetables, and you are deciding on the order in which you will do the various things you need to do. You are in a big hurry.

At the moment you have a slight urge to cut vegetables. If you first start the water boiling and then cut the vegetables you will be done in twenty minutes. If you cut the vegetables and then start the water boiling you will be done in forty minutes.

Would you cut the vegetables first and then start the water boiling in order to satisfy your slight urge to cut vegetables?

\section{Shower}

You are planning to attend a luncheon this afternoon, and before you go you will need to take a shower. You have some yard work that you would like to do before then, and doing this yard will cause you to perspire a fair amount.

If you shower before you do your yard work you will have to take another shower before the luncheon. At the present time you could enjoy taking a shower. At the same time, 
you have a very strong commitment to lowering your water bill and to showering no more than once a day.

Would you shower before doing your yard work in order to enjoy a shower now?

\section{Impersonal Moral Scenarios:}

\section{Standard Trolley Mean emotion rating: 5.3}

You are at the wheel of a runaway trolley quickly approaching a fork in the tracks. On the tracks extending to the left is a group of five railway workmen. On the tracks extending to the right is a single railway workman.

If you do nothing the trolley will proceed to the left, causing the deaths of the five workmen. The only way to avoid the deaths of these workmen is to hit a switch on your dashboard that will cause the trolley to proceed to the right, causing the death of the single workman.

Would you hit the switch in order to avoid the deaths of the five workmen?

\section{Standard Fumes Mean emotion rating: 5.5}

You are the late-night watchman in a hospital. Due to an accident in the building next door, there are deadly fumes rising up through the hospital's ventilation system. In a certain room of the hospital are three patients. In another room there is a single patient. If you do nothing the fumes will rise up into the room containing the three patients and cause their deaths.

The only way to avoid the deaths of these patients is to hit a certain switch, which will cause the fumes to bypass the room containing the three patients. As a result of doing this the fumes will enter the room containing the single patient, causing his death.

Would you hit the switch in order to avoid the deaths of the three patients?

\section{Vaccine Policy Mean emotion rating: 1.1}

You work for the Bureau of Health, a government agency. You are deciding whether or not your agency should encourage the use of a certain recently developed vaccine. The vast majority of people who take the vaccine develop an immunity to a certain deadly disease, but a very small number of people who take the vaccine will actually get the disease that the vaccine is designed to prevent. 
All the available evidence, which is very strong, suggests that the chances of getting the disease due to lack of vaccination are much higher than the chances of getting the disease by taking the vaccine.

Would you direct your agency to encourage the use of this vaccine in order to promote national health?

\section{Sculpture Mean emotion rating: 3.1}

You are visiting the sculpture garden of a wealthy art collector. The garden overlooks a valley containing a set of train tracks. A railway workman is working on the tracks, and an empty runaway trolley is heading down the tracks toward the workman.

The only way to save the workman's life is to push one of the art collector's prized sculptures down into the valley so that it will roll onto the tracks and block the trolley's passage. Doing this will destroy the sculpture.

Would you destroy the sculpture in order to save this workman's life?

\section{Speedboat Mean emotion rating: 3.0}

While on vacation on a remote island, you are fishing from a seaside dock. You observe a group of tourists board a small boat and set sail for a nearby island. Soon after their departure you hear over the radio that there is a violent storm brewing, a storm that is sure to intercept them.

The only way that you can ensure their safety is to warn them by borrowing a nearby speedboat. The speedboat belongs to a miserly tycoon who would not take kindly to your borrowing his property.

Would you borrow the speedboat in order to warn the tourists about the storm?

\section{Guarded Speedboat Mean emotion rating: 3.0}

While on vacation on a remote island, you are fishing from a seaside dock. You observe a group of tourists board a small boat and set sail for a nearby island. Soon after their departure you hear over the radio that there is a violent storm brewing, a storm that is sure to intercept them.

The only way that you can ensure their safety is to warn them by borrowing a nearby speedboat. The speedboat belongs to a miserly tycoon who has hired a fiercely loyal guard to make sure that no one uses his boat without permission. To get to the speedboat you will have to lie to the guard. 
Would you lie to the guard in order to borrow the speedboat and warn the tourists about the storm?

\section{Resume Mean emotion rating: 2.8}

You have been trying to find a job lately without much success. You figure that you would be more likely to get hired if you had a more impressive resume.

You could put some false information on your resume in order to make it more impressive. By doing this you might ultimately manage to get hired, beating out several candidates who are actually more qualified than you.

Would you put false information on your resume in order to help yourself find employment?

\section{Taxes Mean emotion rating: 2.7}

You are the owner of a small business trying to make ends meet. It occurs to you that you could lower your taxes by pretending that some of your personal expenses are business expenses.

For example, you could pretend that the stereo in your bedroom is being used in the lounge at the office, or that your dinners out with your wife are dinners with clients.

Would you pretend that certain personal expenses are business expenses in order to lower your taxes?

\section{Stock Tip Mean emotion rating: 2.6}

You are a management consultant working on a case for a large corporate client. You have access to confidential information that would be very useful to investors. You have a friend who plays the stock market. You owe this friend a sizable sum of money.

By providing her with certain confidential information you could help her make a lot of money, considerably more than you owe her. If you did this, she would insist on canceling your debt. Releasing information in this way is strictly forbidden by federal law.

Would you release this information to your friend so that she will cancel your debt?

10. Illegal Lunch Mean emotion rating: 2.1 
You are a lawyer working on a big case. The judge presiding over the trial happens to be someone you knew from law school. The two of you were rather friendly back then, but now, decades later, it seems that your old friend barely remembers you.

You're quite sure that if you were to talk to him over lunch, you could jog his memory and he would begin to see you as an old buddy, which would be very good for your work on this case. It's illegal for judges and lawyers working on the same case to meet socially.

Would you meet with this judge socially in order to help you win your case?

\section{Lost Wallet Mean emotion rating: 2.9}

You are walking down the street when you come across a wallet lying on the ground. You open the wallet and find that it contains several hundred dollars in cash as well the owner's driver's license.

From the credit cards and other items in the wallet it's very clear that the wallet's owner is wealthy. You, on the other hand, have been hit by hard times recently and could really use some extra money. You consider sending the wallet back to the owner without the cash, keeping the cash for yourself.

Would you keep the money you found in the wallet in order to have more money for yourself? 


\section{Personal Moral Scenarios:}

\section{Country Road Mean emotion rating: $5.4 \quad$ Low-conflict}

You are driving along a country road when you hear a plea for help coming from some roadside bushes. You pull over and encounter a man whose legs are covered with blood. The man explains that he has had an accident while hiking and asks you to take him to a nearby hospital.

Your initial inclination is to help this man, who will probably lose his leg if he does not get to the hospital soon. However, if you give this man a lift, his blood will ruin the leather upholstery of your car.

Would you leave this man by the side of the road in order to preserve your leather upholstery?

\section{Plane Crash Mean emotion rating: 6.6 Low-conflict}

Your plane has crashed in the Himalayas. The only survivors are yourself, another man, and a young boy. The three of you travel for days, battling extreme cold and wind. Your only chance at survival is to find your way to small a village on the other side of the mountain, several days away.

The boy has a broken leg and cannot move very quickly. His chances of surviving the journey are essentially zero. Without food, you and the other man will probably die as well. The other man suggests that you sacrifice the boy and eat his remains over the next few days.

Would you kill this boy so that you and the other man may survive your journey to safety?

\section{Hired Rapist Mean emotion rating: 6.5 Low-conflict}

You have been dissatisfied with your marriage for several years. It is your distinct impression that your wife no longer appreciates you. You remember how she appreciated you years ago when you took care of her after she was mugged. You devise the following plan to regain your wife's affection.

You will hire a man to break into your house while you are away. This man will tie up your wife and rape her. You, upon hearing the horrible news, will return swiftly to her side, to take care of her and comfort her, and she will once again appreciate you. 
Would you hire a man to rape your wife so that she will appreciate you as you comfort her?

\section{Infanticide Mean emotion rating: 6.7 Low-conflict}

You are a fifteen-year-old girl who has become pregnant. By wearing loose clothing and deliberately putting on weight you have managed to keep your pregnancy a secret. One day, while at school, your water breaks. You run to the girls locker room and hide for several hours while you deliver the baby. You are sure that you are not prepared to care for this baby.

You think to yourself that it would be such a relief to simply clean up the mess you've made in the locker room, wrap the baby in some towels, throw the baby in the dumpster behind the school, and act as if nothing had ever happened.

Would you throw your baby in the dumpster in order to move on with your life?

\section{Architect Mean emotion rating: 6.2 Low-conflict}

You are a young architect visiting one of your construction sites with your boss. Your boss is a despicable individual who makes everyone around him miserable including you.

It occurs to you that if you were to push him off of the building you are inspecting he would fall to his death and everyone would think it was an accident.

Would you push your boss off of the building in order to get him out of your life?

\section{Hard Times Mean emotion rating: 5.8 Low-conflict}

You are the head of a poor household in a developing country. Your crops have failed for the second year in a row, and it appears that you have no way to feed your family. Your sons, ages eight and ten, are too young to go off to the city where there jobs, but your daughter could fare better.

You know a man from your village who lives in the city and who makes sexually explicit films featuring small children such as your daughter. He tells you that in one year of working in his studio your daughter could earn enough money to keep your family fed for several growing seasons.

Would you employ your daughter in the child pornography industry in order to feed your family? 


\section{Transplant Mean emotion rating: $6.0 \quad$ Low-conflict}

You are a doctor. You have five patients, each of whom is about to die due to a failing organ of some kind. You have another patient who is healthy.

The only way that you can save the lives of the first five patients is to transplant five of this young man's organs (against his will) into the bodies of the other five patients. If you do this, the young man will die, but the other five patients will live.

Would you perform this transplant in order to save five of your patients?

8. Smother for dollars Mean emotion rating: $5.9 \quad$ Low-conflict

You are in hospital lounge waiting to visit a sick friend. A young man sitting next to you explains that his father is very ill. The doctors believe that he has a week to live at most. He explains further that his father has a substantial life insurance policy that expires at midnight.

If his father dies before midnight, this young man will receive a very large sum of money. He says that the money would mean a great deal to him and that no good will come from his father's living a few more days. He offers you half a million dollars to go up to his father's room and smother his father with a pillow.

Would you kill this man's father in order to get money for yourself and this young man?

\section{Sacrifice Mean emotion rating: 6.7 High-conflict}

You, your husband, and your four children are crossing a mountain range on your return journey to your homeland. You have inadvertently set up camp on a local clan's sacred burial ground.

The leader of the clan says that according to the local laws, you and your family must be put to death. However, he will let yourself, your husband, and your three other children live if you yourself will kill your oldest son.

Would you kill your oldest son in order to save your husband and your other three children?
10. Crying Baby
Mean emotion rating: 6.8
High-conflict

Enemy soldiers have taken over your village. They have orders to kill all remaining civilians. You and some of your townspeople have sought refuge in the cellar of a large 
house. Outside you hear the voices of soldiers who have come to search the house for valuables.

Your baby begins to cry loudly. You cover his mouth to block the sound. If you remove your hand from his mouth his crying will summon the attention of the soldiers who will kill you, your child, and the others hiding out in the cellar. To save yourself and the others you must smother your child to death.

Would you smother your child in order to save yourself and the other townspeople?
11. Footbridge
Mean emotion rating: 6.0
High-conflict

A runaway trolley is heading down the tracks toward five workmen who will be killed if the trolley proceeds on its present course. You are on a footbridge over the tracks, in between the approaching trolley and the five workmen. Next to you on this footbridge is a stranger who happens to be very large.

The only way to save the lives of the five workmen is to push this stranger off the bridge and onto the tracks below where his large body will stop the trolley. The stranger will die if you do this, but the five workmen will be saved.

Would you push the stranger on to the tracks in order to save the five workmen?

\section{Vaccine Test Mean emotion rating: 5.8 High-conflict}

A viral epidemic has spread across the globe killing millions of people. You have developed two substances in your home laboratory. You know that one of them is a vaccine, but you don't know which one. You also know that the other one is deadly.

Once you figure out which substance is the vaccine you can use it to save millions of lives. You have with you two people who are under your care, and the only way to identify the vaccine is to inject each of these people with one of the two substances. One person will live, the other will die, and you will be able to start saving lives with your vaccine.

Would you kill one of these people with a deadly injection in order to identify a vaccine that will save millions of lives?

\section{Sophie's Choice Mean emotion rating: 6.6 High-conflict}

It is wartime and you and your two children, ages eight and five, are living in a territory that has been occupied by the enemy. At the enemy's headquarters is a doctor who performs painful experiments on humans that inevitably lead to death. 
He intends to perform experiments on one of your children, but he will allow you to choose which of your children will be experimented upon. You have twenty-four hours to bring one of your children to his laboratory. If you refuse to bring one of your children to his laboratory he will find them both and experiment on both of them.

Would you bring one of your children to the laboratory in order to avoid having them both die?

\section{Lifeboat 2 Mean emotion rating: $5.1 \quad$ High-conflict}

You are on a cruise ship when there is a fire on board, and the ship has to be abandoned. The lifeboats are carrying many more people than they were designed to carry. The lifeboat you're in is sitting dangerously low in the water-a few inches lower and it will sink.

The seas start to get rough, and the boat begins to fill with water. If nothing is done it will sink before the rescue boats arrive and everyone on board will die. However, there is an injured person who will not survive in any case. If you throw that person overboard the boat will stay afloat and the remaining passengers will be saved.

Would you throw this person overboard in order to save the lives of the remaining passengers?

\section{Ecologists Mean emotion rating: $6.1 \quad$ High-conflict}

You are part of a group of ecologists who live in a remote stretch of jungle. The entire group, which includes eight children, has been taken hostage by a group of paramilitary terrorists. One of the terrorists takes a liking to you. He informs you that his leader intends to kill you and the rest of the hostages the following morning.

He is willing to help you and the children escape, but as an act of good faith he wants you to kill one of your fellow hostages whom he does not like. If you refuse his offer all the hostages including the children and yourself will die. If you accept his offer then the others will die in the morning but you and the eight children will escape.

Would you kill one of your fellow hostages in order to escape from the terrorists and save the lives of the eight children?
16. Vitamins
Mean emotion rating: 5.8
High-conflict 
You are the leader of a mountaineering expedition that is stranded in the wilderness. Your expedition includes a family of six that has a genetically caused vitamin deficiency. A few people's kidneys contain large amounts of this vitamin.

There is one such person in your party. The only way to save the lives of the six members of this family is to remove one of this man's kidneys so that the necessary vitamins may be extracted from it. The man will not die if you do this, but his health will be compromised. The man is opposed to this plan, but you have the power to do as you see fit.

Would you forcibly remove this man's kidney in order to save the lives of the six vitamin-deficient people?

\section{Euthanasia Mean emotion rating: 5.5 High-conflict}

You are the leader of a small group of soldiers. You are on your way back from a completed mission deep in enemy territory when one of your men has stepped in trap that has been set by the enemy and is badly injured. The trap is connected to a radio device that by now has alerted the enemy to your presence. They will soon be on their way.

If the enemy finds your injured man they will torture him and kill him. He begs you not to leave him behind, but if you try to take him with you your entire group will be captured. The only way to prevent this injured soldier from being tortured is to shoot him yourself.

Would you shoot this soldier in order to prevent him from being tortured by the enemy?

\section{Lawrence of Arabia Mean emotion rating: 6.1 High-conflict}

You are the leader of a small army that consists of warriors from two tribes, the hill tribe and the river tribe. You belong to neither tribe. During the night a hill tribesman got into an argument with a river tribesman and murdered him. The river tribe will attack the hill tribe unless the murderer is put to death, but the hill tribe refuses to kill one of its own warriors.

The only way for you to avoid a war between the two tribes that will costs hundreds of lives is to publicly execute the murderer by cutting off is head with your sword.

Would you cut off this man's head in order to prevent the two tribes from fighting a war that will cost hundreds of lives?

19. Submarine Mean emotion rating: 5.3 High-conflict 
You are the captain of a military submarine travelling underneath a large iceberg. An onboard explosion has caused you to lose most of your oxygen supply and has injured one of your crew who is quickly losing blood. The injured crew member is going to die from his wounds no matter what happens.

The remaining oxygen is not sufficient for the entire crew to make it to the surface. The only way to save the other crew members is to shoot dead the injured crew member so that there will be just enough oxygen for the rest of the crew to survive.

Would you kill the fatally injured crew member in order to save the lives of the remaining crew members?

\section{Bomb $2 \quad$ Mean emotion rating: 5.3 High-conflict}

You are negotiating with a powerful and determined terrorist who is about to set off a bomb in a crowded area. Your one advantage is that you have his teen-age son in your custody.

There is only one thing that you can do to stop him from detonating his bomb, which will kill thousands of people if detonated. To stop him, you must contact him over the satellite hook-up that he has established and, in front of the camera, break one of his son's arms and then threaten to break the other one if he does not give himself up.

Would you break the terrorist's son's arm in order to prevent the terrorist from killing thousands of people with his bomb?

\section{Preventing the Spread 2 Mean emotion rating: 4.3 High-conflict}

You are a waiter. You overhear one of your customers say that he is about to go to jail and that in his last forty-eight hours of freedom he plans to infect as many people as possible with HIV. You know him well enough to know that he is telling the truth and that he has access to many potential victims.

You happen to know that he has a very strong allergy to poppy seeds. If he eats even one he will go into convulsions and have to be hospitalized for at least forty-eight hours.

Would you cause this man to have a serious allergy attack in order to prevent him from spreading HIV? 